\title{
Characterization of Municipal, Construction and Demolition Wastes for Energy Production Through Gasification - A Case Study for a Portuguese Waste Management Company
}

\author{
Octávio Alves ${ }^{1,2(\triangle)}(\mathbb{D})$, Jeysa Passos $^{2}(D)$, Paulo Brito ${ }^{2}$ (D), \\ Margarida Gonçalves $^{1,2}$ (D), and Eliseu Monteiro ${ }^{2}$ (D) \\ ${ }^{1}$ MEtRICs - Mechanical Engineering and Resource Sustainability Center, \\ Department of Science and Technology of Biomass, Faculty of Science \\ and Technology, Universidade NOVA de Lisboa, Lisbon, Portugal \\ o.alves@campus.fct.unl.pt \\ ${ }^{2}$ VALORIZA - Research Center for Endogenous Resource Valorisation, \\ Polytechnic Institute of Portalegre, Portalegre, Portugal
}

\begin{abstract}
Gasification of wastes is considered a promising alternative for energy generation due to its lower environmental impacts when compared with conventional landfilling and incineration. Valorisation of such wastes improves sustainability of resource management and of energy production. However, an appropriate characterisation of wastes in terms of physical and chemical properties is essential for the prediction of their behaviour during gasification, allowing to identify possible problems for the environment and installed equipment and also to define which materials present a greater energy potential. This study aimed to characterise 10 different fractions from municipal, construction and demolition wastes received in different fluxes by a Portuguese waste management company. These fractions included wood $(44.83 \mathrm{wt} \%)$, plastic (22.15 wt \%), paper/card (0.04 wt \%), mixtures of paper and plastic (14.67 $\mathrm{wt} \%)$ and sewage sludge $(18.31 \mathrm{wt} \%)$. For this purpose, determination of density, proximate and ultimate analysis, higher heating value (HHV), thermogravimetric profiles and inorganic composition of ashes were performed for each fraction. Analysis revealed that plastics and their mixtures with paper/card possess the highest HHV's (25-45 MJ/kg db), thus exhibiting a greater capacity for energy production. High levels of ashes found in dried sewage sludge (50 wt $\% \mathrm{db}$ ) indicate that a lot of by-product will be generated after gasification, possibly increasing the treatment costs. A gasification unit operating at $50 \mathrm{~kg} / \mathrm{h}$ and admitting a mixture of all these wastes would generate $109.7 \mathrm{~kW}$ of total power, having capacity to receive more waste fluxes along the year.
\end{abstract}

Keywords: Municipal solid waste $\cdot$ Construction and demolition waste Property analysis - Gasification 


\section{Introduction}

Traditional methods for the treatment and disposal of wastes like landfilling, incineration or application in agriculture raise several health and environmental concerns. Recent European directives like 2008/98/EC and the future RED II for 2021-2030 have encouraged the adoption of new waste-to-energy solutions using advanced technologies [1]. In this context, gasification may be considered a valid alternative. It consists in a thermochemical conversion of wastes at c.a. $800{ }^{\circ} \mathrm{C}$ with limited amounts of oxygen to produce a combustible gas (syngas) that can be used for energy production. The process has lower toxic gas emissions than incineration and may reduce the dependence on fossil fuels [2]. The implementation of a gasification unit implies a good knowledge about the properties of wastes in order to estimate the potential energy that will be generated and to predict possible issues for the equipment and health: for example, chlorine and alkali metals are known to cause corrosion and obstruction problems [3, 4]. Knowledge of these properties is required for an adequate choice of pre-treatments and components for the facility. Municipal solid (MSW) and construction and demolition wastes (CDW) are heterogeneous residual fluxes containing organic fractions like plastics, wood and paper/card, all of them viable for gasification due to the good calorific values. A few works may be found in the literature that focused on the characterization and classification of the different materials present in wastes $[1,5]$. The present study aimed to evaluate the physical and chemical properties of 10 distinct and separated fractions present in MSW and CDW received by a Portuguese waste management company, in order to evaluate the contribution of each fraction to the overall gasification process.

\section{Materials and Methods}

Waste samples were collected in a Portuguese waste management company and are identified in Table 1, along with their corresponding code number in the European list of wastes (ELW) and with the waste amounts received and processed during 2015.

Table 1. Identification and received amounts of wastes by the company (year 2015).

\begin{tabular}{l|l|l|l}
\hline Sample & ELW number & Brief description & Amount $(\mathrm{kg})$ \\
\hline R1 & 170201 & Wood (CDW) & 56910 \\
\hline R2 & 200138 & Wood (MSW) & 4280 \\
\hline R3 & 200101 & Paper/card (MSW) & 50 \\
\hline R4 & 150102 & Plastic packages & 13840 \\
\hline R5 & 150105 & Composite packages $(99.9 \%$ paper $+0.1 \%$ plastic) & 7850 \\
\hline R6 & 150106 & Mixture of packages $(65 \%$ paper/card $+35 \%$ plastic) & 12180 \\
\hline R7 & 170203 & Plastics (CDW) & 4400 \\
\hline R8 & 200139 & Plastics (MSW) & 7820 \\
\hline R9 & 170604 & Polymeric insulations (CDW) & 4180 \\
\hline L1 & 200306 & Sludges from sewage cleaning & 25000 \\
\hline
\end{tabular}


Since samples R4 and R8 were similar in composition, analysis of R8 was excluded and considered equivalent to R4. The solid wastes (i.e. all but the sludges) were crushed, milled and sieved in particle sizes of c.a. $12 \mathrm{~mm},<0.425 \mathrm{~mm}$ and $<0.250 \mathrm{~mm}$. The first-class size was used to determine bulk density (according to EN 15103), the second for moisture content (ASTM E949-88) and the third for a thermogravimetric analysis under a $\mathrm{N}_{2}$ atmosphere (using a PerkinElmer STA 6000). Samples R4 and R6 were highly malleable and thus were not possible to be milled in small grains; instead, they were cut with scissors until the minimum size that was possible to reach. Sludge was analyzed as received for the determination of moisture content and thermogravimetric profile, however a different method was employed to determine density $(2710 \mathrm{~F}$ from Standard Methods). Then the sludge was completely dried at $105{ }^{\circ} \mathrm{C}$ and milled to produce grains of $<0.425 \mathrm{~mm}$. Posteriorly, all samples with $<0.425 \mathrm{~mm}$ were dried at $105{ }^{\circ} \mathrm{C}$ in order to determine their higher heating value (HHV, with a IKA C200) and their ultimate analysis (in a ThermoFisher Scientific Flash 2000 CHNS-O). Contents of volatile matter, ash and fixed carbon were measured following ASTM E897-88, ASTM E830-87 and calculated by difference, respectively. Inorganic composition of ashes was analysed by X-ray fluorescence using a Thermo Scientific Niton XL 3T Gold++.

\section{Results and Discussion}

Analysis of the received waste fluxes reported in Table 1 indicated that woods from RCD (R1) and sludges (L1) were the most representative, with weight fractions $>18 \mathrm{wt}$ $\%$ ar. Paper/card waste was almost negligible (0.04 wt \% ar). Table 2 shows the results obtained for density, HHV and proximate analysis of each sample.

Table 2. Density, HHV and proximate analysis of sample wastes.

\begin{tabular}{l|l|l|l|l|l|l}
\hline Sample & $\begin{array}{l}\text { Density } \\
\left(\mathrm{kg} / \mathrm{m}^{3} \mathrm{ar}\right)\end{array}$ & $\begin{array}{l}\text { HHV } \\
(\mathrm{MJ} / \mathrm{kg} \mathrm{db})\end{array}$ & $\begin{array}{l}\text { Moisture } \\
(\mathrm{wt} \% \mathrm{ar})\end{array}$ & $\begin{array}{l}\text { Volatiles } \\
(\mathrm{wt} \% \mathrm{db})\end{array}$ & $\begin{array}{l}\text { Fixed } \\
\text { carbon } \\
(\mathrm{wt} \% \mathrm{db})\end{array}$ & $\begin{array}{l}\text { Ash } \\
(\mathrm{wt} \% \mathrm{db})\end{array}$ \\
\hline R1 & 253 & 18.9 & 10.9 & 88.0 & 9.3 & 2.7 \\
\hline R2 & 286 & 19.4 & 12.7 & 89.3 & 9.4 & 1.3 \\
\hline R3 & 37 & 14.9 & 6.2 & 82.0 & 0.0 & 18.3 \\
\hline R4/R8 & 26 & 44.9 & 0.6 & 98.0 & 0.0 & 2.5 \\
\hline R5 & 25 & 17.0 & 6.1 & 94.5 & 0.0 & 6.1 \\
\hline R6 & 43 & 26.5 & 4.3 & 85.7 & 5.2 & 9.1 \\
\hline R7 & 543 & 25.0 & 0.4 & 81.8 & 7.2 & 10.9 \\
\hline R9 & 19 & 30.3 & 1.0 & 93.6 & 4.4 & 1.9 \\
\hline L1 & 1070 & 24.6 & 89.2 & 47.9 & 2.3 & 49.8 \\
\hline
\end{tabular}

HHV was greater for plastic materials (R4, R8, R7 and R9) and for the mixture of plastics + paper/card (R6), with values ranging from $25-45 \mathrm{MJ} / \mathrm{kg} \mathrm{db}$, indicating that these wastes possess high energy levels available for gasification. However, they also 
present the lowest densities ( $\leq 26 \mathrm{~kg} / \mathrm{m} 3$ ), and therefore rise costs of transportation from collection points to the gasification plant. Waste R7 (CDW) had the most balanced results among HHV's and densities $(25 \mathrm{MJ} / \mathrm{kg} \mathrm{db}$ and $543 \mathrm{~kg} / \mathrm{m} 3$, respectively), thus being a material that may be directly used while others should be mixed to dilute undesirable characteristics. Considering that gasification generally admits materials with moisture contents less than $15 \mathrm{wt} \%$, all wastes are appropriate for the process with the exception of $\mathrm{L} 1$ ( $89 \mathrm{wt} \%$ ar) that must be submitted to an intensive drying pre-treatment. There is no apparent correspondence between HHV and volatile matter: for example, plastics R4, R8 and R9 possess high values in both parameters ( $>30 \mathrm{MJ} / \mathrm{kg} \mathrm{db}$ and $>93$ $\mathrm{wt} \% \mathrm{db}$, respectively), but on the contrary the composite waste R5 has a lower HHV and a high volatile matter content $(17 \mathrm{MJ} / \mathrm{kg} \mathrm{db}$ and $95 \mathrm{wt} \% \mathrm{db})$.

Ash contents were significantly larger in the case of L1 (sludge), achieving almost $50 \mathrm{wt} \% \mathrm{db}$. This may be a problem because a lot of inorganic by-product is generated during gasification what imposes the need of convenient post-treatment or disposal methods, thus increasing operational costs. Therefore, a definition of valorisation pathways for these ashes is relevant, namely, it may be opportune to study their application in remediation of effluents or their use in agriculture.

The mixture of paper/card with plastics (R6) seems to be advantageous for gasification because it not only reduced the ash content ( 18 to $9 \mathrm{wt} \% \mathrm{db}$ ) but also increased the HHV (15 to $27 \mathrm{MJ} / \mathrm{kg} \mathrm{db}$ ), when compared with paper/card alone (R3).

Table 3 shows the measured results for ultimate analysis, $\mathrm{H} / \mathrm{C}$ and $\mathrm{O} / \mathrm{C}$ ratios.

Table 3. Ultimate analysis and atomic ratios $\mathrm{O} / \mathrm{C}$ and $\mathrm{H} / \mathrm{C}$ of sample wastes.

\begin{tabular}{|c|c|c|c|c|c|c|c|}
\hline \multirow[t]{2}{*}{ Sample } & \multicolumn{5}{|c|}{ Element (wt $\% \mathrm{db}$ ) } & \multicolumn{2}{|c|}{$\begin{array}{l}\text { Atomic } \\
\text { ratio }(\mathrm{db})\end{array}$} \\
\hline & $\mathrm{N}$ & C & $\mathrm{H}$ & $S$ & $\mathrm{O}$ & $\mathrm{O} / \mathrm{C}$ & $\mathrm{H} / \mathrm{C}$ \\
\hline $\mathrm{R} 1$ & 2.0 & 45.8 & 5.8 & 0.0 & 43.7 & 0.95 & 0.13 \\
\hline $\mathrm{R} 2$ & 0.1 & 47.8 & 6.0 & 0.0 & 44.8 & 0.94 & 0.13 \\
\hline R3 & 0.3 & 38.6 & 5.2 & 0.1 & 37.5 & 0.97 & 0.13 \\
\hline $\mathrm{R} 4 / \mathrm{R} 8$ & 0.0 & 83.9 & 14.0 & 0.0 & 0.0 & 0.00 & 0.17 \\
\hline $\mathrm{R} 5$ & 0.2 & 40.2 & 5.4 & 0.1 & 48.0 & 1.19 & 0.13 \\
\hline R6 & 0.0 & 41.8 & 5.9 & 0.0 & 43.2 & 1.03 & 0.14 \\
\hline R7 & 0.3 & 50.9 & 6.6 & 0.1 & 31.2 & 0.61 & 0.13 \\
\hline R9 & 3.3 & 70.9 & 7.4 & 0.0 & 16.5 & 0.23 & 0.10 \\
\hline L1 & 0.1 & 33.4 & 4.6 & 0.4 & 11.7 & 0.35 & 0.14 \\
\hline
\end{tabular}

Typically, lower $\mathrm{O} / \mathrm{C}$ and $\mathrm{H} / \mathrm{C}$ ratios are associated with solid fossil fuels like vegetable coal, meaning that materials with lower ratios present greater HHV's [6]. As seen in Table 3, all samples have similar $\mathrm{H} / \mathrm{C}$ ratios but show some variations in $\mathrm{O} / \mathrm{C}$ ratios, so this last parameter apparently has a higher impact on $\mathrm{HHV}$. In fact, plastic samples $\mathrm{R} 4, \mathrm{R} 8$ and $\mathrm{R} 9$ possess the lowest $\mathrm{O} / \mathrm{C}$ ratios $(<0.3)$ which justify the highest HHV's determined in Table 2. On the other hand, wood samples R1 and R2, paper/card R3 and composite R5 showed higher O/C ratios $(>0.9)$ that decreased their 
HHV's. Mixture R6 seems to escape to this rule, possibly because problems of homogenization of its constituents occurred during the determination of ultimate analysis and which were associated to the difficulty of obtaining fine grains. The corresponding $\mathrm{O} / \mathrm{C}$ ratio (1.03) did not agree well with the literature (0.7 [7]). Contents of $\mathrm{S}$ were relatively low for the generality of wastes $(\leq 0.4 \mathrm{wt} \% \mathrm{db})$ and therefore formation of toxic compounds $\mathrm{SO}_{2}$ and $\mathrm{H}_{2} \mathrm{~S}$ during gasification would be negligible. However, wastes R1 and R9 possess high quantities of $\mathrm{N}$ ( $\geq 2 \mathrm{wt} \% \mathrm{db}$ ) that promotes the formation of $\mathrm{NO}_{\mathrm{x}}$ gases, so a careful regulation of the $\mathrm{O}_{2}$ injected in the gasifier must be done. Table 4 presents the composition of ashes of all wastes in terms of the relevant inorganic oxides.

Table 4. Inorganic composition of ashes derived from waste samples.

\begin{tabular}{l|l|l|l|l|l|l|l|l|l|l}
\hline \multirow{2}{*}{ Sample } & \multicolumn{2}{l}{ Oxide $(\mathrm{wt} \%)$} \\
\cline { 2 - 12 } & $\mathrm{Al}_{2} \mathrm{O}_{3}$ & $\mathrm{CaO}$ & $\mathrm{CuO}$ & $\mathrm{Fe}_{2} \mathrm{O}_{3}$ & $\mathrm{~K}_{2} \mathrm{O}$ & $\mathrm{P}_{2} \mathrm{O}_{5}$ & $\mathrm{SO}_{3}$ & $\mathrm{SiO}_{2}$ & $\mathrm{TiO}_{2}$ & $\mathrm{ZnO}$ \\
\hline $\mathrm{R} 1$ & 0.0 & 26.5 & 0.9 & 5.5 & 4.1 & 1.3 & 3.2 & 8.1 & 1.9 & 0.4 \\
\hline $\mathrm{R} 2$ & 0.0 & 30.6 & 0.3 & 3.0 & 7.4 & 2.3 & 2.3 & 4.0 & 0.6 & 0.2 \\
\hline $\mathrm{R} 3$ & 3.3 & 40.7 & 0.1 & 1.6 & 0.1 & 0.0 & 1.6 & 9.6 & 0.4 & 0.1 \\
\hline $\mathrm{R} 4 / \mathrm{R} 8$ & 0.0 & 29.1 & 0.2 & 3.9 & 1.6 & 0.0 & 2.5 & 9.9 & 4.1 & 0.4 \\
\hline $\mathrm{R} 5$ & 0.0 & 34.7 & 0.2 & 3.1 & 1.1 & 0.0 & 3.7 & 7.9 & 0.8 & 0.1 \\
\hline $\mathrm{R} 6$ & 2.1 & 35.4 & 0.1 & 1.5 & 0.3 & 0.0 & 1.0 & 8.9 & 0.6 & 0.1 \\
\hline $\mathrm{R} 7$ & 0.0 & 19.8 & 0.0 & 1.2 & 0.1 & 0.5 & 4.4 & 3.8 & 6.7 & 0.0 \\
\hline $\mathrm{R} 9$ & 0.0 & 16.7 & 0.3 & 9.7 & 0.6 & 2.7 & 0.7 & 39.4 & 0.9 & 1.6 \\
\hline $\mathrm{L} 1$ & 7.6 & 9.0 & 0.0 & 6.2 & 2.5 & 1.8 & 4.1 & 35.7 & 0.7 & 0.2 \\
\hline
\end{tabular}

Generally, $\mathrm{CaO}$ and $\mathrm{SiO}_{2}$ were the most representative oxides with mass fractions that achieved around $40 \mathrm{wt} \%$. Compositions were similar for samples of woods (R1 and R2) and those based on paper/card (R3 and R5), but they differed significantly in the case of polymers (R4, R7, R8 and R9). The relatively high concentrations of $\mathrm{CaO}$ (26-31 wt \%), $\mathrm{P}_{2} \mathrm{O}_{5}(1-3 \mathrm{wt} \%), \mathrm{Fe}_{2} \mathrm{O}_{3}(3-6 \mathrm{wt} \%)$ and $\mathrm{K}_{2} \mathrm{O}(4-8 \mathrm{wt} \%)$ found in wood ash make them viable for fertilization or $\mathrm{pH}$ correction in agriculture, but it is necessary to ensure that heavy metals remain under the legal limits by applying appropriate decontamination post-treatments. Figure 1 presents the thermogravimetric profiles and derivative curves obtained for four different samples in terms of structure and composition (R1, R6, R7 and L1). The first concavity in the derivative curve corresponds to the release of moisture, notably higher for sample L1 and almost absent for sample R7. The weight loss between $300-400{ }^{\circ} \mathrm{C}$ is generally high for lignocellulosic materials due to the degradation of hemicellulose and cellulose fibers, a behavior observed for R1 and R6 samples. On the other hand, R7 showed a wider range of decomposition temperatures (300-500 ${ }^{\circ} \mathrm{C}$ ), corresponding to the pyrolytic decomposition between $300{ }^{\circ} \mathrm{C}$ and $400{ }^{\circ} \mathrm{C}$ followed by the char volatilization and oxidation in the range from $400{ }^{\circ} \mathrm{C}$ to $500{ }^{\circ} \mathrm{C}$, a behavior frequently observed for polymeric materials [8, 9].

Regarding R6 (mixture of paper/card and plastic), two pronounceable concavities were found: the first reports to the decomposition of the lignocellulosic structures of 

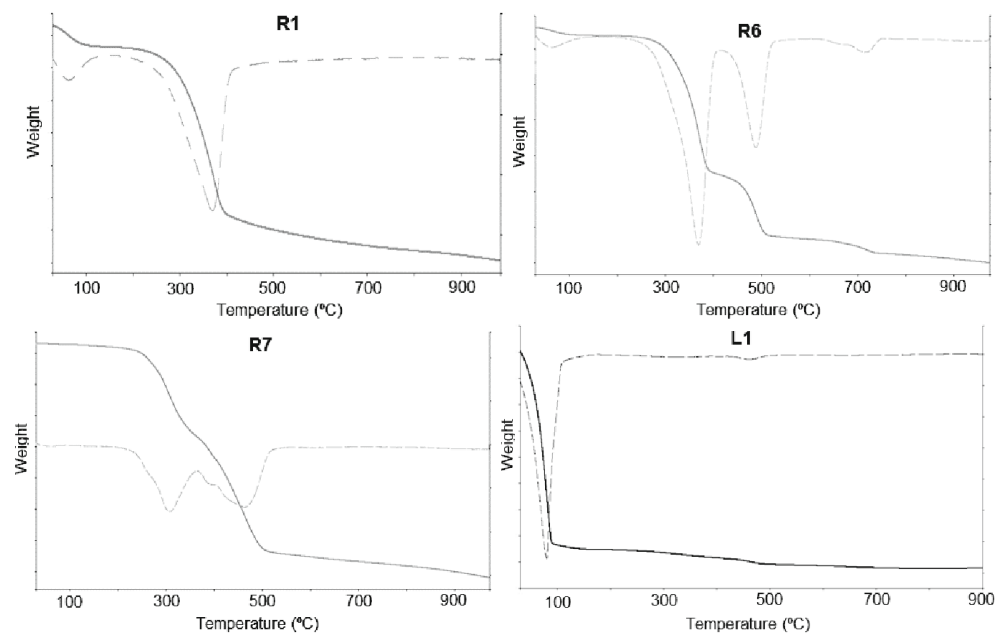

Fig. 1. Thermogravimetric profiles for samples R1, R6, R7 and L1 (continuous line represents the loss of mass while the dashed one is the derivative).

paper/card and the second to plastics. According to these profiles, if a pre-treatment of carbonization for enhancing waste properties is to be considered (particularly in the case of polymers), then it must be performed at temperatures $\leq 300{ }^{\circ} \mathrm{C}$ to avoid a significant loss of mass. A fuel mixture containing all these wastes in the proportions mentioned in Table 1 would have an average HHV of $25.2 \mathrm{MJ} / \mathrm{kg} \mathrm{db}$ and an average ash content of $12 \mathrm{wt} \% \mathrm{db}$. For a gasification unit operating continuously at $50 \mathrm{~kg} / \mathrm{h}$ and producing $0.916 \mathrm{Nm}^{3}$ of syngas per $\mathrm{kg}$ of compound with a lower heating value of $8.62 \mathrm{MJ} / \mathrm{Nm}^{3}$, then it would generate 16.5 ton of ash and $109.7 \mathrm{~kW}$ of total power. Operation time would be short (114 days/year), meaning that the unit would be able to receive higher quantities of waste therefore expanding its activity.

\section{Conclusions}

A characterization of the properties of 10 distinct wastes received by a Portuguese waste management company was carried out in this study in order to evaluate their potential use for energy generation through gasification. It was concluded that plastic wastes and their mixtures with paper/card showed the highest HHV's, thus exhibiting good capacity for energy conversion. High ash contents found in dried sewage sludge may promote the formation of large quantities of inorganic by-product that has to be treated, increasing the overall costs. A possible pre-treatment of carbonization of all wastes must be executed at no more than $300{ }^{\circ} \mathrm{C}$ in order to avoid an appreciable loss of mass. A gasification unit projected to operate at $50 \mathrm{~kg} / \mathrm{h}$ and admitting a mixture of these wastes would produce $109.7 \mathrm{~kW}$ of total power. The total amount of wastes is insufficient to keep the unit working continuously all the year, and therefore it is capable to receive more waste fluxes eventually from other sources. Determination of 
chlorine contents of all wastes (especially in the case of plastics) is relevant and suggested for future works with the aim of evaluating possible problems for equipment and to define appropriate decontamination treatments.

Acknowledgements. Authors acknowledge the financial support received by the Foundation for Science and Technology from the Portuguese Ministry of Science, Technology and Higher Education (grant no. SFRH/BD/111956/2015), and project POCI-01-0145-FEDER-024020 (RDFGAS - Aproveitamento energético dos combustíveis derivados de resíduos e lamas secas), co-financed by COMPETE 2020 - Programa Operacional Competitividade e Internacionalização, Portugal 2020 and União Europeia through FEDER. An acknowledgement is sent to the company Pragosa Ambiente, S. A. for providing the waste samples, and also to Luís Calado, Bruno Garcia, Miltiadis Samanis and Paula Rodrigues.

\section{References}

1. Zhou, H., Meng, A., Long, Y., Li, Q., Zhang, Y.: Classification and comparison of municipal solid waste based on thermochemical characteristics. JAPCA J. Air Waste Manag. Assoc. 64 (5), 597-616 (2014)

2. Di Fraia, S., Massaroutti, N., Vanoli, L., Costa, M.: Thermo-economic analysis of a novel cogeneration system for sewage sludge treatment. Energy 115, 1560-1571 (2016)

3. Silva, R., Fragoso, R., Sanches, C., Costa, M., Martins-Dias, S.: Which chlorine ions are currently being quantified as total chlorine on solid alternative fuels? Fuel Process. Technol. 128, 61-67 (2014)

4. Asadullah, M.: Biomass gasification gas cleaning for downstream applications: a comparative critical review. Renew. Sustain. Energy Rev. 40, 118-132 (2014)

5. Zhou, H., Meng, A., Long, Y., Li, Q., Zhang, Y.: An overview of characteristics of municipal solid waste fuel in China: physical, chemical composition and heating value. Renew. Sustain. Energy Rev. 36, 107-122 (2014)

6. Prins, M., Ptasinski, K., Janssen, F.: More efficient biomass gasification via torrefaction. Energy 31, 3458-3470 (2006)

7. Kobayashi, J., Kawamoto, K., Fukushima, R., Tanaka, S.: Woody biomass and RPF gasification using reforming catalyst and calcium oxide. Chemosphere 83, 1273-1278 (2011)

8. Xu, J., Liu, C., Qu, H., Ma, H., Jiao, Y., Xie, J.: Investigation on the thermal degradation of flexible poly(vinyl chloride) filled with ferrites as flame retardant and smoke suppressant using TGA-FTIR and TGA-MS. Polym. Degrad. Stab. 98, 1506-1514 (2013)

9. Ali, M., Qureshi, M.: Transportation fuels from catalytic co-pyrolysis of plastic wastes with petroleum residues: evaluation of catalysts by thermogravimetric analysis. Pet. Sci. Technol. 31(16), 1665-1673 (2013) 